\title{
A NEW DESIGN EQUATION FOR PREDICTION OF ULTIMATE BEARING CAPACITY OF SHALLOW FOUNDATION ON GRANULAR SOILS
}

\author{
Ehsan SADROSSADAT ${ }^{\mathrm{a}}$, Fazlollah SOLTANI ${ }^{\mathrm{a}}$, Seyyed Mohammad MOUSAVI ${ }^{\mathrm{b}}$, \\ Seyed Morteza MARANDI ${ }^{\mathrm{c}}$, Amir H. ALAVI ${ }^{\mathrm{d}}$ \\ ${ }^{a}$ Department of Civil Engineering, Kerman Graduate University of Technology, Kerman, Iran \\ ${ }^{b}$ Department of Geography and Urban Planning, Science and Research branch, \\ Islamic Azad University, Tehran, Iran \\ ${ }^{c}$ Department of Civil Engineering, Bahonar University, Kerman, Iran \\ ${ }^{d}$ Department of Civil and Environmental Engineering, Engineering Building, \\ Michigan State University, East Lansing, MI 48824, USA
}

Received 30 Dec 2011; accepted 20 Feb 2012

\begin{abstract}
A major concern in design of structures is to provide precise estimations of ultimate bearing capacity of soil beneath their foundations. Direct determination of the bearing capacity of foundations requires performing expensive and time consuming laboratory tests. To cope with this issue, several numerical models have been presented by researchers. This paper presents the development of a new design equation for the prediction of the ultimate bearing capacity of shallow foundations on granular soils using linear genetic programming (LGP) methodology. The ultimate bearing capacity is formulated in terms of width of footing, footing geometry, depth of footing, unit weight of sand, and angle of shearing resistance. The LGP-based design equation is established using the results of several load tests on real sized foundations presented in the literature. Validity of the model is verified using a part of laboratory data that are not involved in the calibration process. The statistical measures of coefficient of determination, root mean squared error and mean absolute error are used to evaluate the performance of the model. Sensitivity and parametric analyses are conducted and discussed. The proposed model accurately characterizes the ultimate bearing capacity resulting in a very good prediction performance. The LGP model reaches a better prediction performance than the well-known prediction equations for the bearing capacity of shallow foundations.
\end{abstract}

Keywords: ultimate bearing capacity, shallow foundations, linear genetic programming, granular soils, prediction.

Reference to this paper should be made as follows: Sadrossadat, E.; Soltani, F.; Mousavi, S. M.; Marandi, S. M.; Alavi, A. H. 2013. A new design equation for prediction of ultimate bearing capacity of shallow foundation on granular soils, Journal of Civil Engineering and Management 19(Supplement 1): S78-S90. http://dx.doi.org/10.3846/13923730.2013.801902

\section{Introduction}

Columns, bearing walls or other bearing members transmit the building loads to foundations. A foundation is the lowest part of a structure which transmits loads to the underlying soil. Considering the depth of construction, the foundations can be classified into two major groups of shallow and deep foundations. A foundation with a depth (D) to width (B) ratio less than or equal to three or four (D/B $\leq 3$ or 4 ) is simply called a "shallow foundation" (Das 1995; Cerato 2005). Fig.1 shows a definition sketch for shallow foundations. In general, any foundation design must meet three essential requirements (Chen, Duan 2000): (1) providing adequate safety against structural failure of the foundation, (2) offering adequate bearing capacity of soil beneath the foundation with a specified safety against ultimate failure, and (3) achieving acceptable total or differential settlements under working loads.
Bearing capacity failure usually occurs in one of the three modes of general shear, local shear, or punching shear failure (Vesic 1973). The ultimate bearing capacity can be defined as the gross pressure at the base of the foundation at which soil fails in shear. Providing a precise estimation of the ultimate bearing capacity of the soil beneath the foundation is crucial for an efficient design.

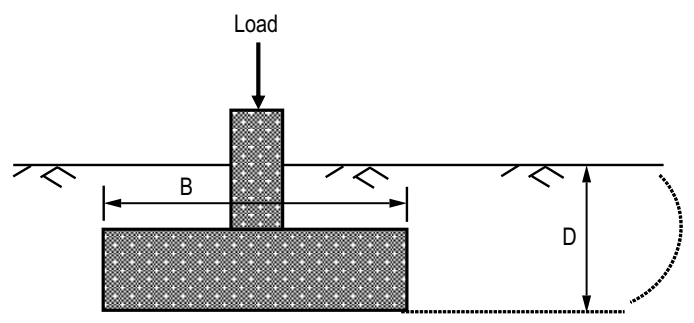

Fig. 1. A typical sketch for shallow foundation

Corresponding author: Amir H. Alavi

E-mail:ah_alavi@hotmail.com; alavi@msu.edu 
Four approaches commonly used to determine the bearing capacity of shallow and deep foundations are (Eslami and Gholami 2006): (1) static analysis, (2) in-situ testing methods, (3) full-scale loading tests, and (4) using presumed values recommended by codes and handbooks. Among these approaches, a theoretical solution (i.e. static analysis) is more common.

In this context, Prandtl (1921) and Reissner (1924) presented methods of calculating the ultimate bearing capacity of shallow strip footings based on the plastic theory. Later, the formulation was considerably developed by other researchers over the years (Terzaghi 1943; Taylor 1948; Meyerhof 1963; Hansen 1968; Vesic 1973; Kalinli et al. 2011). Terzaghi (1943) extended the theory of Prandtl (1921) by taking into account the weight of soil by the principle of superposition. Taylor (1948) incorporated the surcharge effect of the overburden soil at the foundation level into the Prandtl's formulation. Meyerhof (1963) extended the Terzaghi's bearing capacity equation by including different shape and depth factors. The Meyerhof' model was later modified by Hansen (1968). Vesic (1973) developed a bearing capacity prediction equation similar to that proposed by Hansen (1968).

Recently, Kalinli et al. (2011) improved the Meyerhof formula by using a parallel ant colony optimization algorithm. The improved Meyerhof formula proposed by Kalinli et al. (2011) found to be more accurate than the theoretical computation formulas. Some of the general forms of the classical equations are summarized in Table 1 . As can be observed from this table, the form of the equations presented by the other researchers remained the same as that of Terzaghi's. After extensive in situ and laboratory tests, Meyerhof (1963), Hansen (1968), Vesic (1973) and several other researchers proposed different shape, depth, inclination, ground, and base factors for the

Table 1. General forms of the classical prediction equations for the bearing capacity of shallow foundations

\begin{tabular}{lc}
\hline Reference & Equation \\
\hline $\begin{array}{l}\text { Terzaghi } \\
(1943)\end{array}$ & $q_{u l t}=c N_{c} s_{c}+\gamma D N_{q}+0.5 \gamma B N_{\gamma} s_{\gamma}$ \\
\hline $\begin{array}{l}\text { Meyerhof } \\
(1963)\end{array}$ & $q_{u l t}=c N_{c} s_{c} d_{c} i_{c}+\gamma D N_{q} s_{q} d_{q} i_{q}+0.5 \gamma B . N_{\gamma} s_{\gamma} d_{\gamma} i_{\gamma}$ \\
\hline $\begin{array}{l}\text { Hansen } \\
(1970)\end{array}$ & $q_{u l t}=c N_{c} s_{c} d_{c} i_{c} g_{c} b_{c}+\gamma D N_{q} s_{q} d_{q} i_{q} g_{q} b_{q}+$ \\
\hline $\begin{array}{l}\text { Vesic } \\
(1975)\end{array}$ & Same as Hansen's equation \\
\hline
\end{tabular}

Notes: $q_{u l t}$ : ultimate unit resistance or bearing capacity of footing; c: cohesion parameter; $\gamma$ : average effective unit weight of the soil below and around the foundation; $B$ : foundation width; $D$ : embedment depth of foundation; $N_{c}, N_{q}$ and $N_{\gamma}$ : non-dimensional bearing capacity factors as exponential functions of $\phi$; $\phi$ : soil internal friction angle; $s_{c}, s_{q}$ and $s_{\gamma}$ : non-dimensional shape factors; $i_{c}, i_{d}$ and $i_{\gamma}$ : non-dimensional inclination factors; $d_{c}, d_{q}$ and $d_{\gamma}$ : non-dimensional depth factors; $g_{c}, g_{q}$ and $g_{\gamma}:$ nondimensional ground factors (base on slope); $b_{c}, b_{q}$ and $b_{\gamma}$ : base factors (tilted base). bearing capacity equations. However, a major drawback of these classical formulations is that some simplifying assumptions are incorporated into their development. Therefore, they do not always provide reliable estimations of the bearing capacity (Cerato 2005; Kalinli et al. 2011).

The complexity of analysis of bearing capacity behavior implies the necessity to utilize alternative prediction methods. Numerous computer-aided modeling tools such as soft computing techniques have been proposed by extending developments in computational software and hardware. Artificial neural networks (ANNs) are one of the most popular branches of the soft computing techniques. In recent years, they have been successfully applied to behavioral modeling of many civil engineering problems (Hoła, Schabowicz 2005; Malinowski et al. 2006; Kaplinski, Janusz 2006; Schabowicz, Hola 2007; Das, Basudhar 2008; Sonmez, Ontepeli 2009; Dikmen, Sonmez 2011). Recently, Padmini et al. (2008) utilized neuro-fuzzy inference system (ANFIS) to predict the ultimate bearing capacity of shallow foundations on cohesionless soils. ANFIS combines the transparent, linguistic representation of a fuzzy system with the learning ability of ANNs. Furthermore, Padmini et al. (2008) conducted a comparative study between ANFIS, ANN and fuzzy inference system (FIS) for the prediction of the ultimate bearing capacity. Kuo et al. (2009) used ANNs to predict the bearing capacity of strip footing on multi-layered cohesive soil. More recently, Kalinli et al. (2011) developed an ANN model to predict the ultimate bearing capacity. Despite the acceptable performance of the ANN-based approaches, they are not capable of producing simplified prediction equations.

Genetic algorithm (GA) is a powerful optimization method based on the principles of genetics and natural selection. GA has been shown to be suitably robust for a wide variety of engineering problems (Baušys, Pankrašovaite 2005; Milani, G., Milani, F. 2008; Šešok, Belevicius 2008; Šešok et al. 2010). Genetic programming (GP) (Koza 1992) is a specialization of GA where the solutions are computer programs rather than binary strings (Banzhaf et al. 1998). Genetic programming (GP) (Koza 1992) is a new alternative approach to overcome the limitations of ANNs. One of the main features of GP over other soft computing tools (e.g. ANNs, ANFIS, etc.) is its ability to generate simplified prediction equations without assuming prior form of the existing relationship (Alavi et al. 2011). For the last decade, GP has been pronounced as a powerful method for simulating the behavior of civil engineering problems (Narendra et al. 2006; Javadi et al. 2006; Tung et al. 2009; Gandomi et al. 2011a; Gandomi and Alavi 2011). Linear genetic programming (LGP) (Brameier, Banzhaf 2007) is a new subset of GP. LGP operates on programs that are represented as linear sequences of instructions of an imperative programming language (Brameier, Banzhaf 2001, 2007). In contrast with GA, classical GP and ANNs, ap- 
plication of LGP in the field of civil engineering is totally new and original (Gandomi et al. 2010; Alavi, Gandomi 2011, 2012).

The paper aims at employing LGP to derive a new design equation for the estimation of the ultimate bearing capacity of shallow foundations. The proposed model relates the bearing capacity to various predictor variables including width of footing, depth of footing, footing geometry, unit weight of sand, and angle of shearing resistance. A database containing 97 load test data is used to calibrate the model.

\section{Methodology}

\section{Linear genetic programming}

GP creates computer programs to solve a problem through simulating the biological evolution of living organisms (Koza 1992). Generally, in GP, inputs and corresponding output data samples are known and the main goal is to find a program that connects them (see Fig. 2) (Weise 2009). Most of the genetic operators used in GA can be implemented in GP with minor changes. The main difference between GP and GA is the representation of the solution. GA creates a string of numbers that represent the solution. The classical GP solutions are computer programs represented as tree structures and expressed in a functional programming language (such as LISP) (Koza 1992; Alavi et al. 2011). In other words, in GP, the evolving programs (individuals) are parse trees than can vary in length throughout the run rather than fixed-length binary strings. The fitness of each program generated by GP is evaluated using a fitness function. Thus, the fitness function is the objective function that GP aims to optimize (Gandomi et al. 2011b).

In addition to classical tree-based GP, there are other types of GP where programs are represented in different ways. These are linear and graph-based GP (Banzhaf et al. 1998). Recently, several linear variants of GP have been developed such as linear genetic programming (LGP) (Brameier, Banzhaf 2007) and multi-expression programming (MEP) (Oltean, Grosan 2003). The linear variants of GP make a clear distinction between the genotype and phenotype of an individual. In these variants, individuals are represented as linear strings (Oltean, Grosan 2003). There are some main reasons for using linear GP. Computers do not naturally run tree-shaped programs. Therefore, slow interpreters have to be used as a part of classical tree-based GP. Conversely, by evolving the binary bit patterns, the use of an expensive interpreter is avoided. Consequently, a linear GP system can run several orders of magnitude faster than comparable interpreting systems. The enhanced speed of the linear variants of GP (e.g. LGP and MEP) permits conducting many runs in realistic timeframes. This leads to deriving consistent and high-precision models with little customization (Francone, Deschaine 2004; Poli et al. 2007; Gandomi et al. 2011b).
LGP is a new subset of GP with a linear structure similar to the DNA molecule in biological genomes. In LGP, expressions of a functional programming language (such as LISP) are substituted by programs of an imperative language (such as $\mathrm{C} / \mathrm{C}++$ ) (Brameier, Banzhaf 2001, 2007). Fig. 3 presents a comparison of structure of a program evolved by LGP and classical GP. As shown in this figure, a linear genetic program can be seen as a data flow graph generated by multiple usage of register content. In classical tree-based GP, the data flow is more rigidly determined by the tree structure of the program (Brameier, Banzhaf 2001; Gandomi et al. 2011b).

In the LGP system described here, a program is interpreted as a variable-length sequence of simple $\mathrm{C}$ instructions. The instruction set or function set of LGP contains arithmetic operations, conditional branches, and function calls. The terminal set of the system is composed of variables and constants. The instructions are restricted to operations that accept a minimum number of constants or memory variables, called registers $(f)$, and assign the result to a destination register, e.g. $f_{0}:=f_{1}+$ 1. A part of a linear genetic program in $\mathrm{C}$ code is represented in Fig. 4. In this figure, register $f[0]$ holds the final program output (Gandomi et al. 2010).

Here are the steps which the LGP system follows for a single run (Brameier, Banzhaf 2007; Gandomi et al. 2010):

1) Initializing a population of randomly generated programs and calculating their fitness values.

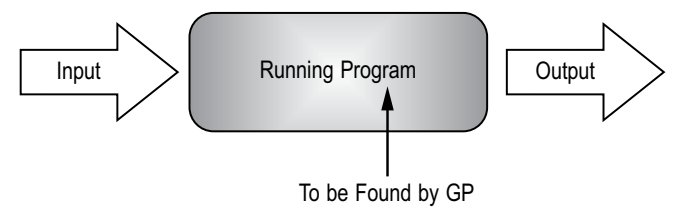

Fig. 2. GP in the context of the input-processing-output model

a)
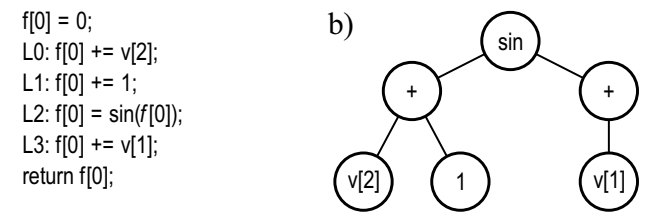

$$
y=f[0]=\sin (v[2]+1)+v[1]
$$

Fig. 3. A comparison of a GP program structure evolved by: (a) LGP; (b) Classical tree-based GP (after Gandomi et al. 2011b)

$$
\begin{aligned}
& \text { L0: } \mathrm{f}[0]=v[1] \\
& \text { L1: } f[0]^{*}=2.5 ; \\
& \text { L2: } \mathrm{f}[0]=v[0] ; \\
& \text { L3: } \mathrm{f}[0]+=v[4] ; \\
& \text { L4: } \mathrm{f}[0]=2.5 ; \\
& \text { L5: } \mathrm{f}[0]=\sin (f[0]) ; \\
& \text { L6: } \mathrm{f}[0]+=f[0] ;
\end{aligned}
$$

Fig. 4. An excerpt of a linear genetic program 
2) Running a Tournament. In this step four programs are selected from the population randomly. They are compared based on their fitness. Two programs are then picked as the winners and two as the losers.

3) Transforming the winner programs. After that, two winner programs are copied and transformed probabilistically into two new programs via crossover and mutation operators.

4) Replacing the loser programs in the tournament with the transformed winner programs. The winners of the tournament remain unchanged.

5) Repeating steps two through four until termination or convergence conditions are satisfied.

a)
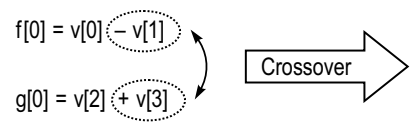

$f^{\prime}[0]=v[0]+v[3]$

$g^{\prime}[0]=v[2]-v[3]$

b) $f[0]=v[0] \bigcirc v[1]$

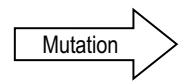

$f^{\prime}[0]=v[0] \bigcirc v[1]$

Fig. 5. Typical variation operations in LGP:

(a) crossover and (b) mutation

Crossover occurs between two or more instruction blocks whereas mutation occurs on a single instruction. Fig. 5 demonstrates typical crossover and mutation in LGP. The crossover operation works by exchanging continuous sequences of instructions between parents. As it is seen in Fig. 5(a), a segment of random position and arbitrary length is selected in each of the two parents $(\mathrm{f}(0)$ and $\mathrm{g}(0))$ and exchanged. If one of the two children would exceed the maximum length, crossover is aborted and restarted with exchanging equally sized segments (Brameier, Banzhaf 2001; Gandomi et al. 2011b). Two commonly used types of standard LGP mutations are micro and macro mutation. The micro mutation changes an operand or an operator of an instruction. The macro mutation operation inserts or deletes a random instruction (Brameier, Banzhaf 2001; Gandomi et al. 2011b).

\section{Numerical simulation of bearing capacity of shallow foundations}

In order to provide reliable estimations of the bearing capacity of shallow foundations, the effect of several parameters should be incorporated into the model development. Considering the basic forms of the existing prediction equations (see Table 1), the bearing capacity of shallow foundations of cohesionless soils mainly depends on the foundation geometry and properties of the soil beneath it (Padmini et al. 2008). The most important parameters related to the geometry of the foundation are its width, length of footing, shape (square, rectangular and circular) and depth of embedment. The significant influence of the soil (sand) physical properties such as angle of shearing resistance and the unit weights from above and below the water table on its bearing capacity is well understood (Padmini et al. 2008). In the present study, the LGP approach is employed to develop a new model relating the ultimate bearing capacity of shallow foundations $\left(q_{u l t}\right)$ and the above mentioned influencing parameters. Consequently, $q_{u l t}(\mathrm{kPa})$ is considered to be a function of the following parameters:

$$
q_{u l t}=f(B, D, L / B, \gamma, \phi),
$$

where: $B(\mathrm{~m})$ : width (least lateral dimension) of footing; $D(\mathrm{~m})$ : depth of footing; $L / B$ : footing geometry; where $\mathrm{L}$ is length of footing; $\gamma\left(\mathrm{kN} / \mathrm{m}^{3}\right)$ : unit weight of soil. If the soil is located above the water table, its dry unit weight $\left(\gamma_{d}\right)$ is used. For the cases where the soil is located below the water table, its effective unit weight $\left(\gamma^{\prime}\right)$ is considered; $\phi\left({ }^{\circ}\right)$ : angle of shearing resistance.

\subsection{Experimental database}

A comprehensive database containing 97 experimental test results from 6 independent studies is obtained from the literature to develop the model. The database consists of 47 load tests on large-scale footings and 50 load tests on small-scale model footings. The large-scale test results are reported by Muhs and Weiß (1971), Weiß (1970), Muhs et al. (1969), Muhs and Weiß (1973), and Briaud and Gibbens (1999). Gandhi (2003) reported the results of the smaller scale model footings. The ultimate load in large-scale tests is defined as the load corresponding to the point where the slope of the load settlement curve is minimum. For small-scale tests, the ultimate load is defined as the load corresponding to the point of break of the load settlement curve in a log-log plot (Padmini et al. 2008). The database includes the results of experiments on square, rectangular and strip footings of different sizes tested in sand beds of various densities. This reliable database has been employed by Padmini et al. (2008) and Kalinli et al. (2011) to develop ANFIS, ANN and FIS-based prediction models for the ultimate bearing capacity. The descriptive statistics of the test results is given in Table 2. To visualize the distribution of the samples, the data are presented by frequency histograms (Fig. 6). As can observe from Fig. 6, the distributions of the predictor variables are not uniform. The frequency histograms present important information about the density of the samples. For instance, the histogram for D indicates that the samples are generally weighted about $0.1 \mathrm{~m}$ (Fig. 6(b)). The LGP model would most probably provide better predictions for such cases where the densities of the variables are higher.

Overfitting is one of the principal problems in generalization of the soft computing methods. It is a case in which the error on the learning set is driven to a very small value, but when new data is presented to the mod$\mathrm{el}$, the error is large. An efficient approach to prevent overfitting is to test other individuals from the run on a validation set to find a better generalization (Banzhaf et al. 1998). This technique is used herein for improving the generalization of the models. For this purpose, the 
a)

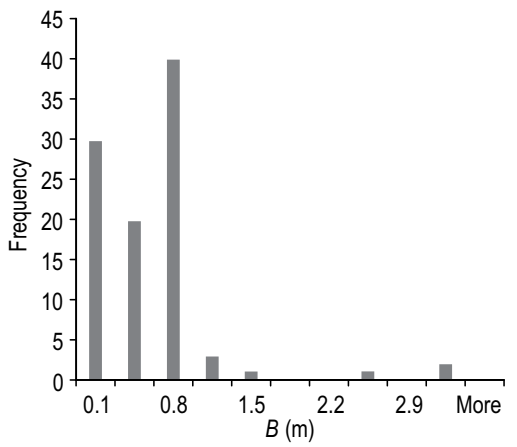

d)

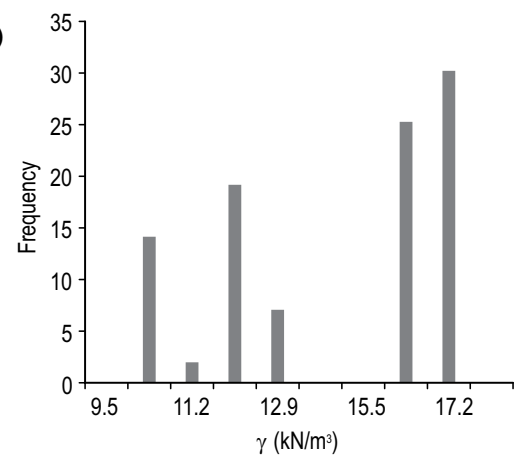

b)

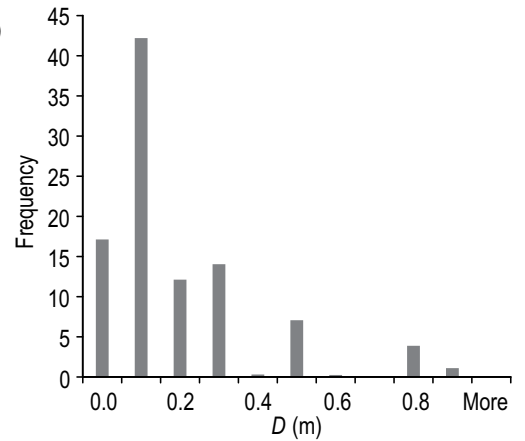

e)

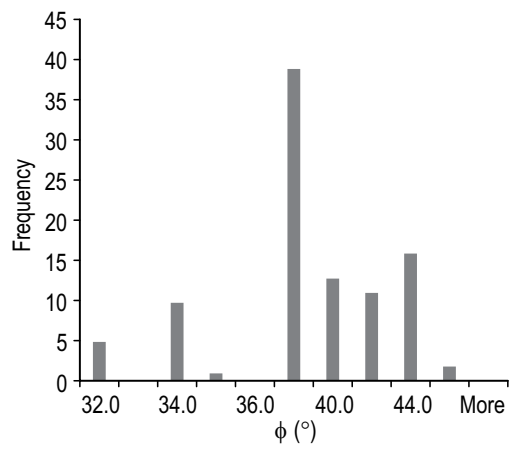

c)

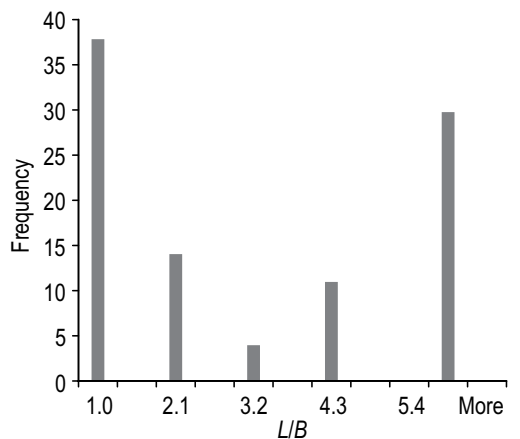

f)

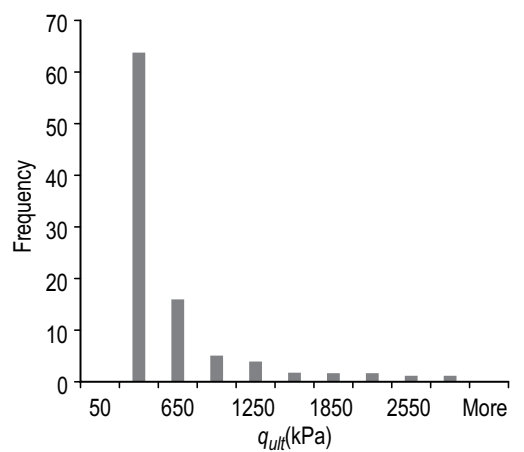

Fig. 6. Histograms of the variables used for the model development

available data sets are randomly divided into three sets: (1) learning, (2) validation, and (3) testing subsets. The learning data are used for the genetic evolution. The validation data are used to specify the generalization capability of the evolved programs on data they did not train on (model selection). In other words, the learning and validation data sets are used to select the best evolved programs and are included in the training process. Thus, they are categorized into one group referred to as training data. Finally, the testing data are used to measure the performance of the models by LGP on data that play no role in building the models (Gandomi et al. 2011b). Of the 97 data, 78 data sets are taken as the training data (69 data vectors for the learning process and 9 data vectors for the validation phase). The remaining 19 sets are used for the testing of the derived models.

\subsection{Parameters for measuring performance}

The parameters used to evaluate the performance of the models are coefficient of determination $\left(\mathrm{R}^{2}\right)$, root mean squared error (RMSE) and mean absolute error (MAE). These parameters are calculated using the following equations:

$$
\mathrm{R}^{2}=\frac{\left(\sum_{i=1}^{n}\left(h_{i}-\overline{h_{i}}\right)\left(t_{i}-\overline{t_{i}}\right)\right)^{2}}{\sum_{i=1}^{n}\left(h_{i}-\overline{h_{i}}\right)^{2} \sum_{i=1}^{n}\left(t_{i}-\overline{t_{i}}\right)^{2}} ;
$$

Table 2. Descriptive statistics of the variables used for the model development

\begin{tabular}{|c|c|c|c|c|c|c|}
\hline Parameter & $B(\mathrm{~m})$ & $D(\mathrm{~m})$ & $\mathrm{L} / \mathrm{B}$ & $\gamma_{d}$ or $\gamma^{\prime}\left(\mathrm{kN} / \mathrm{m}^{3}\right)$ & $\phi\left({ }^{\circ}\right)$ & $q_{u l t}(\mathrm{kPa})$ \\
\hline Mean & 0.40 & 0.165 & 3.100 & 14.18 & 38.55 & 439.6 \\
\hline Standard Error & 0.05 & 0.020 & 0.217 & 0.266 & 0.33 & 53.9 \\
\hline $\begin{array}{l}\text { Standard } \\
\text { Deviation }\end{array}$ & 0.51 & 0.200 & 2.140 & 2.623 & 3.27 & 530.8 \\
\hline $\begin{array}{l}\text { Sample } \\
\text { Variance }\end{array}$ & 0.26 & 0.040 & 4.578 & 6.880 & 10.74 & 281832 \\
\hline Kurtosis & 15.3 & 2.767 & -1.62 & -1.62 & -0.64 & 6.1 \\
\hline Skewness & 3.6 & 1.774 & 0.373 & -0.355 & -0.03 & 2.46 \\
\hline Range & 2.95 & 0.889 & 5.0 & 7.25 & 12.80 & 2788.5 \\
\hline Minimum & 0.05 & 0.000 & 1.0 & 9.85 & 32 & 58.5 \\
\hline Maximum & 3.01 & 0.889 & 6.0 & 17.10 & 44.8 & 2847 \\
\hline
\end{tabular}




$$
\begin{gathered}
\text { RMSE }=\sqrt{\frac{\sum_{i=1}^{n}\left(h_{i}-t_{i}\right)^{2}}{n}} \times 100 ; \\
\text { MAE }=\left[\frac{1}{n} \sum_{i=1}^{n}\left|h_{i}-t_{i}\right|\right],
\end{gathered}
$$

where: $h_{i}$ and $t_{i}$ are the actual and predicted output values for the $i^{t h}$ output, respectively. $\bar{h}_{i}$ and $\bar{t}_{i}$ are, respectively, the average of the actual and predicted outputs, and $n$ is the number of samples.

\subsection{LGP-Based Prediction Model for Bearing Capacity}

The available database is used for establishing the LGP prediction model relating $q_{u l t}$ to $B, D, L / B, \gamma$, and $\phi$. Several runs are conducted to obtain a parameterization of LGP that provided enough robustness and generalization. The LGP parameters are changed for different runs. The parameters are selected on the basis of both previously suggested values (Francone 1998-2004; Baykasoglu et al. 2008; Gandomi et al. 2010) and making several preliminary runs and observing the performance behavior. Three optimal levels are set for the population size $(500,2000$ and 3000) and two levels are considered for the crossover and mutation rate $(50 \%$ and $95 \%)$. The success of the LGP algorithm usually increases with increasing the initial and maximum program size parameters. In this case, the complexity of the evolved functions increases and the speed of the algorithm decreases. The initial program size is set to 80 bytes. Two optimal values $(128,256)$ are considered for the maximum program size as tradeoffs between the running time and the complexity of the evolved solutions. Two values $(10,20)$ are set for the number of demes. This parameter is related to the way that the population of programs is divided. Note that demes are semi-isolated subpopulations that evolution proceeds faster in them in comparison to a single population of equal size (Brameier, Banzhaf 2007). In this study, four basic arithmetic operators $(+,-, \times, /)$ and basic mathematical functions $(\sqrt{ })$ are utilized to get the optimum LGP models. There are $3 \times 2 \times 2 \times 2 \times 2=$ 48 different combinations of the parameters. All of these parameter combinations are tested and 5 replications for each are carried out. Therefore, the overall number of individual runs is equal to $48 \times 5=240$. The termination criterion for each run is based on the number of generations that run has gone without improving. In this study, the number of generations without improvement is set to 600. Each run is observed while in progress for overfitting. For this aim, situations are checked in which the fitness of the samples for the learning of LGP is negatively correlated with the fitness on the validation data sets. To evaluate the fitness of the evolved program, the average of the squared raw errors is used. For the runs showing signs of overfitting, the LGP parameters re progressively changed so as to reduce the computational power available to the LGP algorithm until the observed overfitting is minimized. The resulting run is then accepted as the production run. For the LGP-based analysis, the Discipulus software (Conrads et al. 2004) is used. The best model is chosen on the basis of a multi-objective strategy as follows:

1) Finding the simplest model, although this is not a predominant factor.

2) Providing the best fitness value on the training (learning and validation) set of data.

The best LGP program obtained at the end of training in $\mathrm{C}++$ is given in Appendix A. This program can be run in $\mathrm{C}++$ environment. The resulting code may be linked to the optimizer and compiled or it may be called from the optimization routines (Deschaine 2000). To facilitate the use of the derived code, it is converted into a functional representation by successive replacements of variables starting with the last effective instruction (Oltean and Grossan 2003). The optimal LGP-based formulation of $q_{u l t}$ is as follows:

$$
q_{u l t}(k P a)=\phi\left(\left(\gamma+\phi+\frac{3.95(\phi-35)^{2}}{L / B}\right) D^{2}+2.5(B(\phi-35)+1)\right) \text {. }
$$

The initial population size, crossover rate, mutation rate, and maximum program size for the optimal run are equal to $500,95 \%, 50 \%$ and 128 , respectively. This run took 2 min and $38 \mathrm{~s}$ on a Pentium 4 personal computer with $3.00 \mathrm{GHz}$ of processor speed and $1 \mathrm{~Gb}$ of memory. Fig. 7 shows a comparison between the experimental and predicted $q_{u l t}$ values.

\section{Discussion of Model Validity}

Smith (1986) suggested the following criteria for evaluating the performance of a model:

- If a model gives correlation coefficient $(\mathrm{R})>0.8$ $\left(\mathrm{R}^{2}>0.64\right)$, a strong correlation exists between the predicted and measured values.

In all cases, the error values (e.g. RMSE and MAE) should be at the minimum. It can be observed from Fig. 7 that the LGP model with high $\mathrm{R}\left(\mathrm{R}^{2}\right)$ and low RMSE and MAE values is able to predict the target values with an acceptable degree of accuracy. The performance of the model on the training and testing data suggests that it has both good predictive ability and generalization performance. The reliability of the models created by LGP is notably dependant on the amount of data used for the training process (Alavi et al. 2011). In this context, Frank and Todeschini (1994) argue that the minimum ratio of the number of objects over the number of selected variables for model acceptability is 3 . Also, they suggest that considering a higher ratio equal to 5 is safer. In the present study, this ratio is higher and is equal to $97 / 5=19.4$. Additionally, new criteria recommended by Golbraikh and Tropsha (2002) are checked for the external validation of the model on the testing data sets. It is suggested that at least one slope of regression lines $\left(k\right.$ or $\left.k^{\prime}\right)$ through 

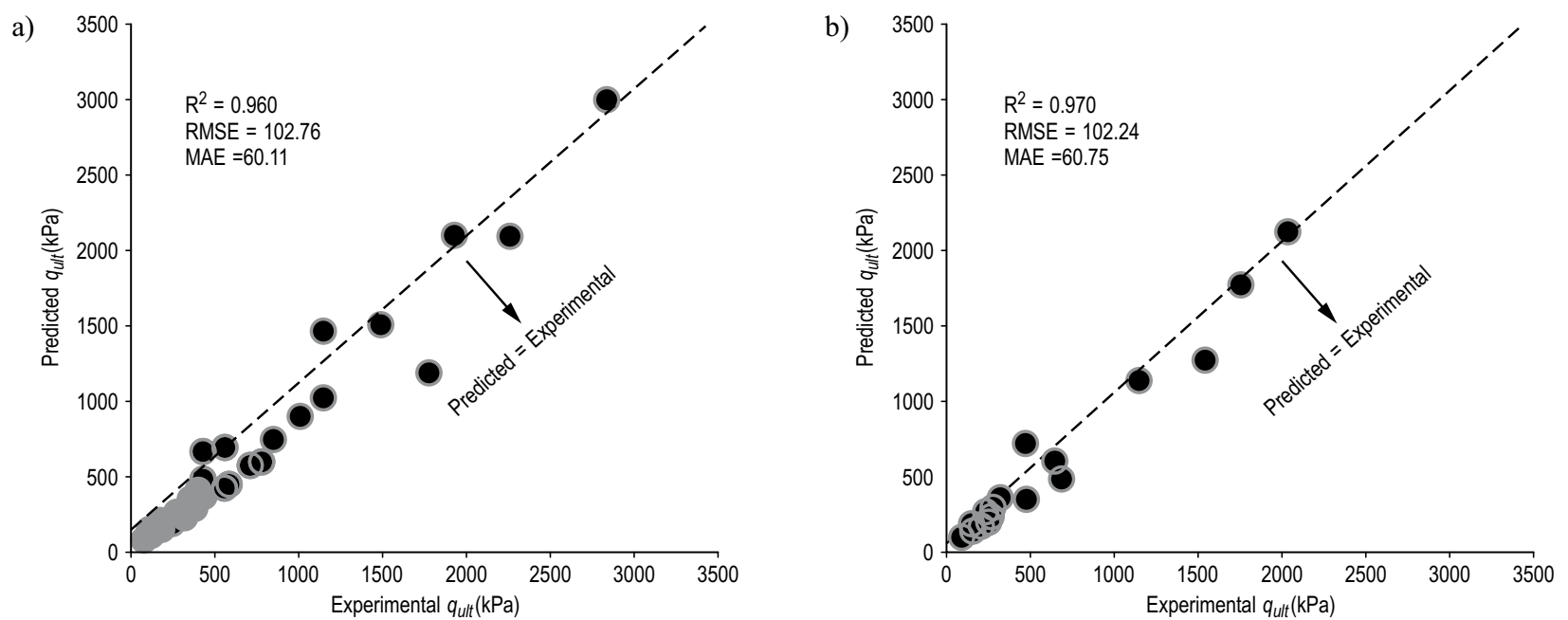

Fig. 7. Experimental versus predicted bearing capacity values using the LGP model: (a) training data, and (b) testing data

the origin should be close to 1 . Also, the performance indexes of $m$ and $n$ should be lower than 0.1. Recently, Roy, P. and Roy, K. (2008) introduced a confirming indicator $\left(\mathrm{R}_{\mathrm{m}}\right)$ for controlling the external predictability of models. For $R_{m}>0.5$, the condition is satisfied. Either the squared correlation coefficient (through the origin) between predicted and experimental values $\left(\mathrm{Ro}^{2}\right)$, or the coefficient between experimental and predicted values (Ro'2) should be close to $\mathrm{R}^{2}$, and to 1 . The considered validation criteria and the relevant results obtained by the models are presented in Table 3. As it is seen in this table, the derived model satisfies all of the required conditions. The validation phase ensures the derived LGP model is strongly valid and it is not established by chance.
In order to have an idea about the predictive power of the LGP model, its performance is compared with that of four traditional models proposed by Terzaghi (1943), Meyerhof (1963), Hansen (1968), and Vesic (1973). Fig. 8 shows a comparison of the predictions made by these models on the testing data sets.

A precise way of observing the systematic mismatches between the predictions and observations is to analyse the residuals, defined as the ratio of the observed to predicted values (Boore, Atkinson 2007). Therefore, in addition to the performance indices described above (i.e. $\mathrm{R}^{2}$, RMSE and MAE), the values of mean (Mean) of the residuals are also shown in Fig. 8. As can be observed from this figure, the proposed formula signifi-

Table 3. Statistical parameters of the LGP model for the external validation

\begin{tabular}{|c|c|c|c|}
\hline Item & Formula & Condition & The proposed model \\
\hline 1 & $R$ & $0.8<R$ & 0.985 \\
\hline 2 & $k=\frac{\sum_{i=1}^{n}\left(h_{i} \times t_{i}\right)}{h_{i}^{2}}$ & $0.85<k<1.15$ & 1.015 \\
\hline 3 & $k^{\prime}=\frac{\sum_{i=1}^{n}\left(h_{i} \times t_{i}\right)}{t_{i}^{2}}$ & $0.85<k^{\prime}<1.15$ & 0.970 \\
\hline 4 & $m=\frac{R^{2}-R o^{2}}{R^{2}}$ & $|m|<0.1$ & -0.030 \\
\hline 5 & $n=\frac{R^{2}-R o^{\prime 2}}{R^{2}}$ & $|n|<0.1$ & -0.029 \\
\hline 6 & $R_{m}=R^{2}\left(1-\sqrt{\left|R^{2}-R o^{2}\right|}\right)$ & $0.5<R_{m}$ & 0.803 \\
\hline where & $\begin{array}{c}R o^{2}=1-\frac{\sum_{i=1}^{n}\left(t_{i}-h_{i}^{o}\right)^{2}}{\sum_{i=1}^{n}\left(t_{i}-\bar{t}_{i}\right)^{2}} \text { and } h_{i}^{o}=k \times t_{i} \\
R o^{\prime 2}=1-\frac{\sum_{i=1}^{n}\left(h_{i}-t_{i}^{o}\right)^{2}}{\sum_{i=1}^{n}\left(h_{i}-\bar{h}_{i}\right)^{2}} \text { and } t_{i}^{o}=k^{\prime} \times h_{i}\end{array}$ & Should be close to 1 & 0.998 \\
\hline
\end{tabular}


cantly outperforms the Terzaghi, Meyerhof, Hansen, and Vesic models. It is worth mentioning that the traditional models are mostly developed using statistical regression techniques. Such models are obtained after controlling only few equations established in advance. Thus, these models cannot efficiently consider the interactions between the dependent and independent variables. On the other hand, LGP introduces completely new features. A major distinction of LGP for determining the bearing capacity lies in its powerful ability to model the mechanical behaviour without requesting a prior form of the existing relationships. The best equation generated by the LGP technique is determined after controlling numerous linear and nonlinear preliminary models. For instance, the proposed design equation is selected among a total of $426,800,992$ programs evolved and evaluated by the LGP method during the conducted 240 runs.

Besides, the results obtained by the ANFIS, FIS (Padmini et al. 2008) and ANN (Kalinli et al. 2011)
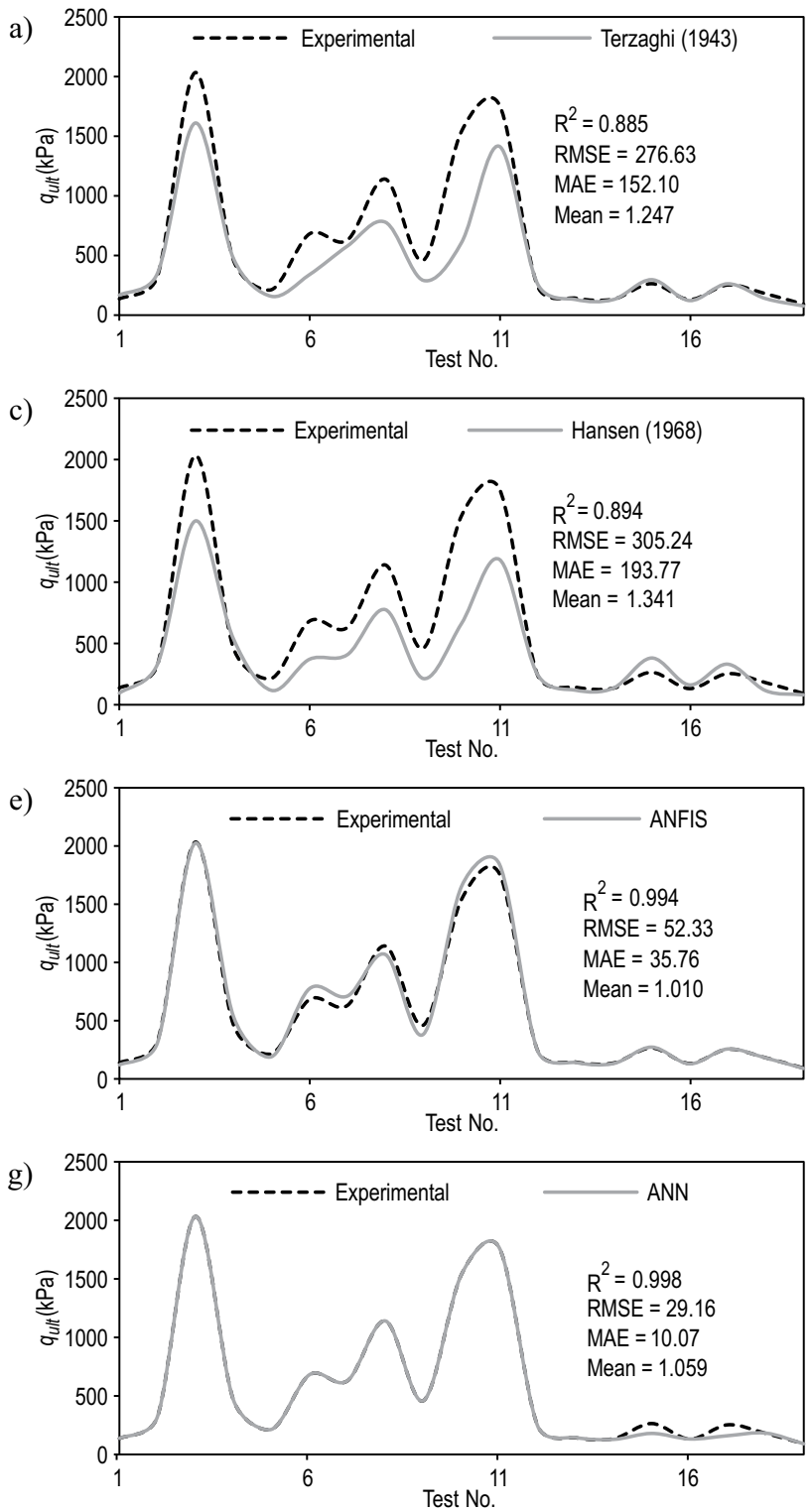

models are included in the comparative study. The predictions made by these models on the testing data sets are presented in Fig. 8. Comparing the $\mathrm{R}^{2}$, RMSE and MAE values for the soft computing tools, it can be seen that the best results are achieved by the ANN model $\left(\mathrm{R}^{2}=\right.$ $0.998, \mathrm{RMSE}=29.16, \mathrm{MAE}=10.07)$ followed by the ANFIS, FIS and LGP solutions. Considering the Mean values, the ANFIS model provides better results than the other models.

Interestingly, in this case, the proposed LGP formulation with a Mean value equal to 1.040 outperforms the ANN $($ Mean $=1.059)$ and FIS $($ Mean $=1.048)$ models.

Although ANN and ANFIS are successful in prediction, they require the structure of the network (e.g. transfer functions, number of hidden layers and neurons) to be identified in advance. This is usually done through a time consuming trial and error procedure. The knowledge extracted by ANNs is stored in a set of weights that cannot properly be interpreted. ANNs do not give a
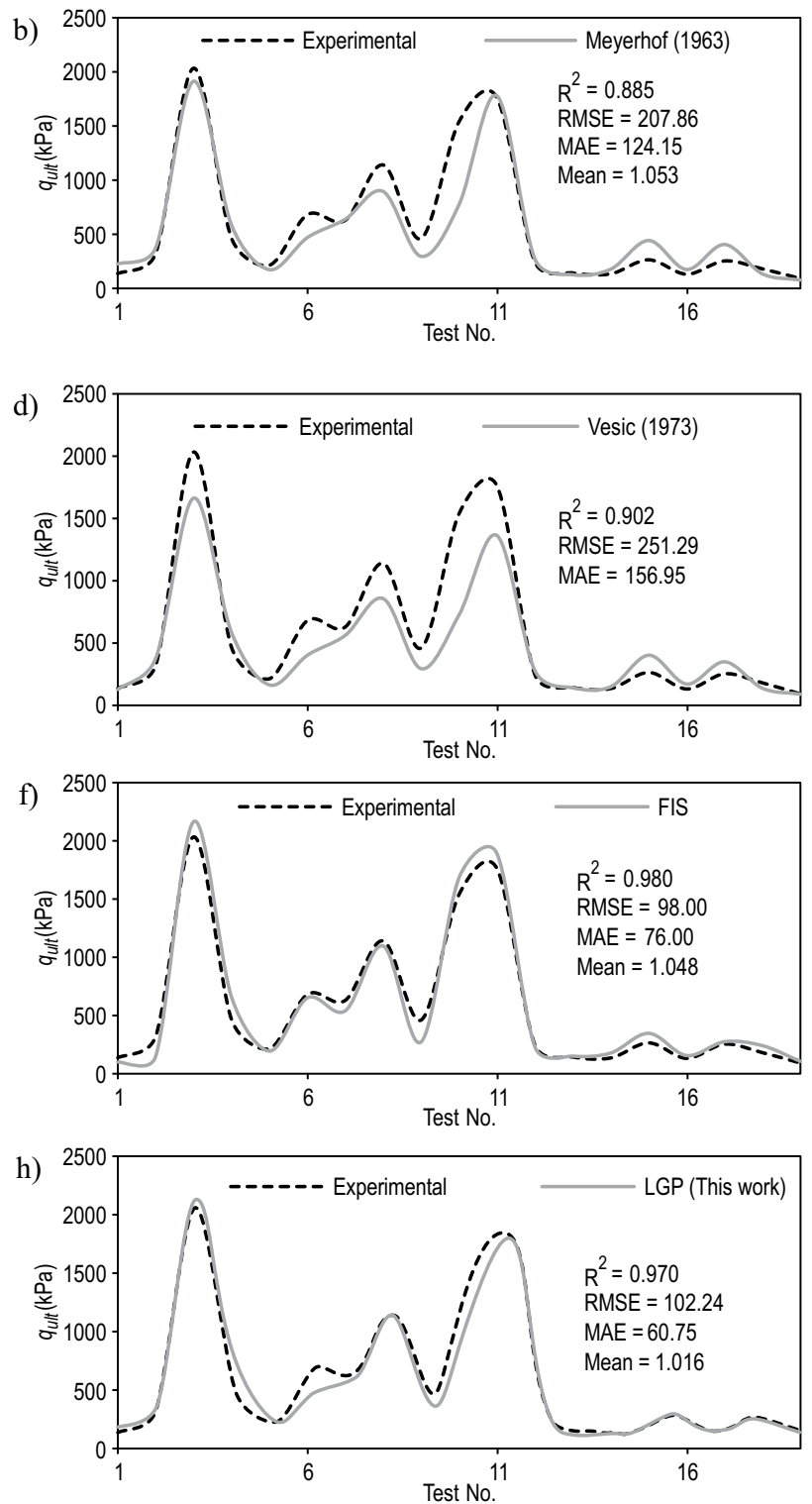

Fig. 8. A comparison of the bearing capacity predictions made by different models 
transparent function because of the large complexity of the network structure. The main advantage of LGP over ANN-based approaches is that it generates a transparent and structured representation of the system being studied. Furthermore, LGP can strongly discriminate between the relevant input data and inputs that have no bearing on the solution. ANNs has little capability in this regard and the variable selection is usually an extensive manual job for the researcher (Francone 1998-2004). The explicit nature of FIS may grant its use for prediction purposes. On the other hand, a fundamental disadvantage of FIS is that determination of the fuzzy rules is a difficult task. However, LGP and other soft computing techniques (e.g. ANNs) are based on the data alone to determine the structure and parameters of the model. Thus, the derived model is considered to be mostly valid for use in preliminary design stages and should cautiously be used for final decision-making. The proposed LGP model is suggested to be used to check the general validity of the laboratory or field test results. Further, the proposed model is a good alternative to determine the ultimate bearing capacity of shallow foundations when testing is not possible.

\section{Sensitivity and Parametric Analyses}

The contributions of the final predictor variables $(B, D$, $L / B, \gamma$, and $\phi)$ in the LGP model are evaluated through a sensitivity analysis. To perform the sensitivity analysis, frequency values of the input parameters are obtained. A frequency value equal to $100 \%$ for an input indicates that this variable has appeared in $100 \%$ of the best thirty programs evolved by LGP. This is a common approach in the GP-based analyses (Gandomi et al. 2011a, b). The

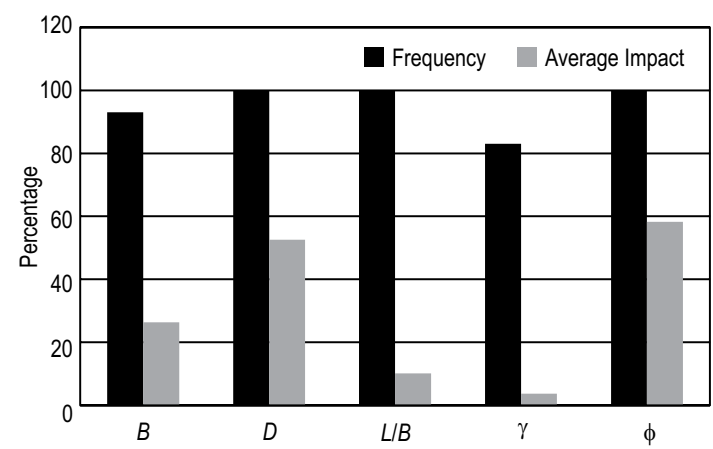

Fig. 9. Contributions of the predictor variables in the LGP analysis

frequency values of the predictor variables are presented in Fig. 8. In addition to frequencies, this figure presents the average impact of removing all instances of each input from the best thirty programs of the project. A value of $100 \%$ represents the largest possible impact value. The greater the value is, the more impact its removal has. As can be observed in Fig. 9, all of the predictor variables have very high frequency values. According to this figure, $q_{u l t}$ is slightly more sensitive to $D, L / B$ and $\phi$ than $B$ and $\gamma$. Also, the average impact of removing $D$ and $\phi$ is higher than the other predictor variables. According to Meyerhof (1950) and Padmini et al. (2008), D and $\phi$ have the greatest effects on the bearing capacity than the other properties of the foundation.

Further, a parametric analysis is performed in this study. The parametric analysis investigates the response of the predicted bearing capacity from the LGP model to a set of predictor variables. The methodology is based on
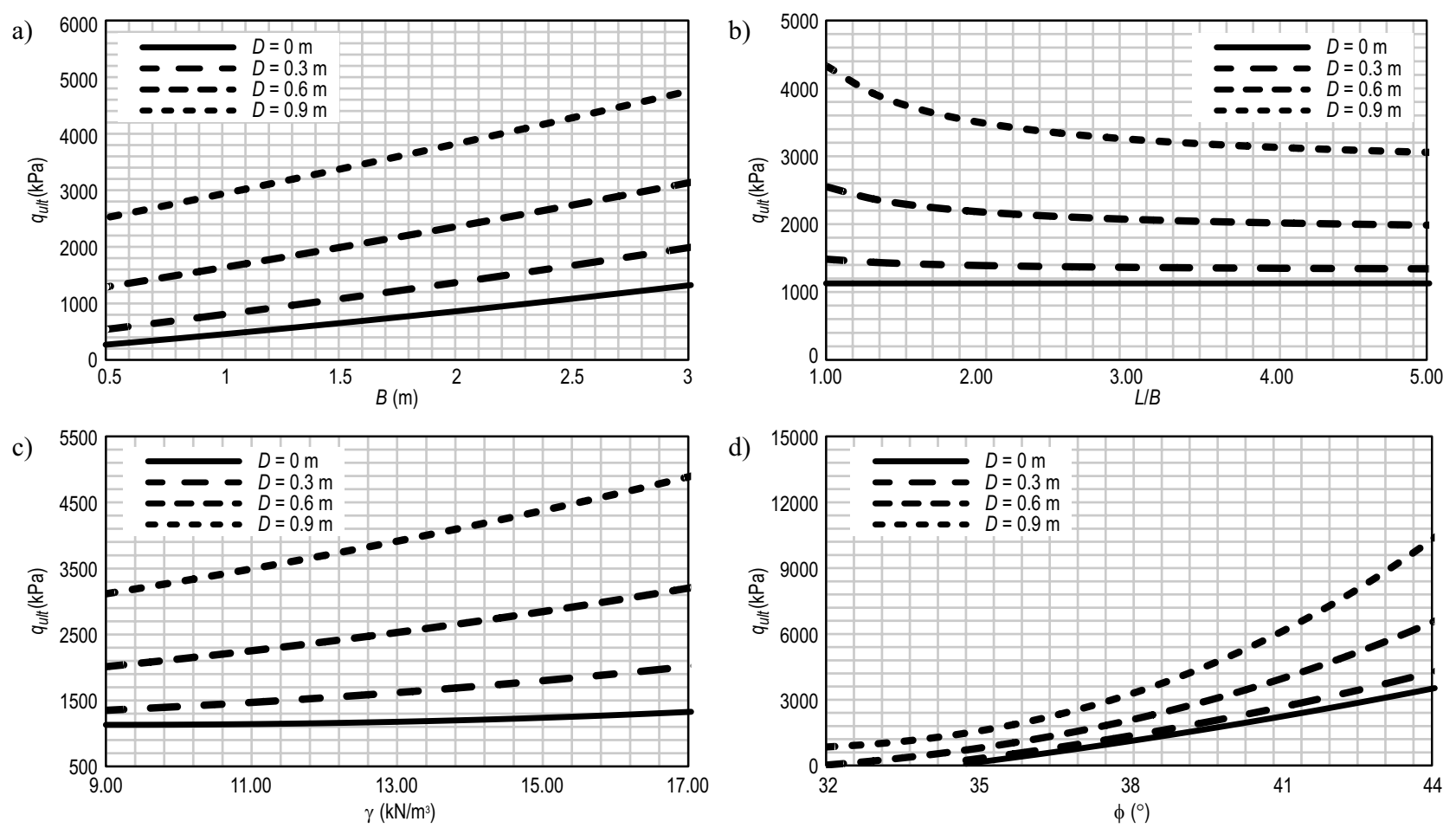

Fig. 10. Parametric analysis of $q_{u l t}$ in the LGP model 
changing only one predictor variable at a time while the other variables are kept constant at the average values of their entire data sets. A set of synthetic data for the single varied parameter is generated by increasing the value of this in increments. These variables are presented to the prediction equations and $q_{u l t}$ is calculated. This procedure is repeated using another variable until the model response is tested for all of the predictor variables (Gandomi et al. 2011b). Fig. 10 presents the tendency of the $q_{u l t}$ predictions to the variations of the influencing parameters, i.e. $B, D, L / B, \gamma$, and $\phi$. These design charts indicate that $q_{u l t}$ continuously increases with increasing $B, D, \gamma$, and $\phi$. Further, it can be observed that $q_{u l t}$ decreases with increasing $L / B$. Interestingly, all of the plotted trends are soundly expected cases from a geotechnical viewpoint.

\section{Conclusions}

In the present study, a new prediction model is derived for the ultimate bearing capacity of shallow foundations using the LGP approach. The proposed model is developed upon several load test results obtained from the literature. The LGP model gives precise estimations of the $q_{u l t}$ values. The validation phases confirm the efficiency of the model for its general application to the bearing capacity estimation. The derived model is mostly suitable for pre-design purposes. It may be used as a quick check on solutions developed by more time consuming and in-depth deterministic analyses. The optimal model takes into account the key role of the width of footing, depth of footing, footing geometry, unit weight of sand, and angle of shearing resistance. The proposed model produces considerably better outcomes over the wellknown models proposed by Terzaghi (1943), Meyerhof (1963), Hansen (1968), Vesic (1973). The values of the performance indices ( $\mathrm{R}^{2}$, RMSE and MAE) indicate that the LGP model does not outperform the ANFIS, FIS and ANN solutions presented in the literature. Considering the values of mean of the residuals, the LGP model performs superior than the FIS and ANN models. However, a major advantage of LGP over ANFIS, FIS and ANN is that it generates a simple equation which can be easily used for prediction purposes via hand calculations. The predictive capability of the derived model is mostly limited to the range of the data used for its calibration. To cope with this limitation, the model can be easily retrained and improved to make more accurate predictions for a wider range by including the data for other test conditions. The proposed model would probably provide better predictions for the situations where the densities of the data considered for the training of the LGP algorithm are higher. A distinctive feature of the LGP-based model is that it is based on the experimental data rather than on assumptions made in developing the conventional models.

\section{References}

Alavi, A. H.; Ameri, M.; Gandomi, A. H.; Mirzahosseini, M. R. 2011. Formulation of flow number of asphalt mixes using a hybrid computational method, Construction and Building Materials 25(3): 1338-1355.

http://dx.doi.org/10.1016/j.conbuildmat.2010.09.010

Alavi, A. H.; Gandomi, A. H. 2011. A robust data mining approach for formulation of geotechnical engineering systems, Engineering Computations 28(3): 242-274. http://dx.doi.org/10.1108/02644401111118132

Alavi, A. H.; Gandomi, A. H. 2012. Energy-based models for assessment of soil liquefaction, Geoscience Frontiers (in press). http://dx.doi.org/10.1016/j.gsf.2011.12.008

Banzhaf, W.; Nordin, P.; Keller, R.; Francone, F. 1998. Genetic programming. An introduction. On the automatic evolution of computer programs and its applications. San Francisco: Morgan Kaufmann Publishers Inc.

Baušys, R.; Pankrašovaite, I. 2005. Optimization of architectural layout by the improved genetic algorithm, Journal of Civil Engineering and Management 11(1): 13-21.

Baykasoglu, A.; Gullub, H.; Canakc1, H.; Ozbakır, L. 2008. Prediction of compressive and tensile strength of limestone via genetic programming, Expert Systems with Applications 35(1-2): 111-123. http://dx.doi.org/10.1016/j.eswa.2007.06.006

Boore, D. M.; Atkinson, G. M. 2007. Boore-Atkinson NGA ground motion relations for the geometric mean horizontal component of peak and spectral ground motion parameters, in PEER Report 2007/01, University of California, Berkeley, California.

Brameier, M.; Banzhaf, W. 2001. A comparison of linear genetic programming and neural networks in medical data mining. IEEE Transactions on Evolutionary Computation 5(1): 17-26. http://dx.doi.org/10.1109/4235.910462

Brameier, M.; Banzhaf, W. 2007. Linear genetic programming. New York: Springer Science + Business Media.

Briaud, J. L.; Gibbens, R. 1999. Behavior of five large spread footings in sand, Journal of Geotechnical and Geoenvironmental Engineering 125(9): 787-796.

http://dx.doi.org/10.1061/(ASCE)1090-0241(1999)125:9(787)

Cerato, A. B. 2005. Scale effects of shallow foundation bearing capacity on granular materials: $\mathrm{PhD}$ dissertation, University of Massachusetts, Amherst.

Chen, W.; Duan, L. 2010. Bridge engineering handbook. CRC Press, New York, N.Y. USA.

Conrads, M.; Dolezal, O.; Francone, F. D.; Nordin, P. 2004. Discipulus - fast genetic programming based on AIM learning technology. Littleton, Colorado: Register Machine Learning Technologies Inc.

Das, B. M. 1995. Principles of foundation engineering. $3^{\text {rd }}$ ed. Boston: PWS Publishing.

Das, S. K.; Basudhar, P. K. 2008. Prediction of residual friction angle of clays using artifical neural network, Engineering Geology 100(3-4): 142-145. http://dx.doi.org/10.1016/j.enggeo.2008.03.001

Deschaine, L. M. 2000. Using genetic programming to develop a $\mathrm{C} / \mathrm{C}++$ simulation model of a waste incinerator science applications, International Corp, Draft Technical Report.

Dikmen, S. U.; Sonmez, M. 2011. An artificial neural networks model for the estimation of formwork labour, Journal of Civil Engineering and Management 17(3): 340-347. http://dx.doi.org/10.3846/13923730.2011.594154

Eslami, A.; Gholami, M. 2006. Analytical model for the ultimate bearing capacity of foundations from cone resistance, Scientia Iranica 13(3): 223-233.

Francone, F. 1998-2004. Discipulus owner's manual. Littleton, Colorado: Register Machine Learning Technologies. 
Francone, F. D.; Deschaine, L. M. 2004. Extending the boundaries of design optimization by integrating fast optimization techniques with machine-code-based, linear genetic programming, Information Sciences 161: 99-120. http://dx.doi.org/10.1016/j.ins.2003.05.006

Frank, I. E.; Todeschini, R. 1994. The data analysis handbook. Amsterdam: Elsevier.

Gandhi, G. N. 2003. Study of bearing capacity factors developed from lab: experiments on shallow footings on cohesionless soils: $\mathrm{PhD}$ thesis, Shri Govindram Seksaria Institute of Technology and Science, Indore (MP), India.

Gandomi, A. H.; Alavi, A. H.; Sahab, M. G. 2010. New formulation for compressive strength of CFRP confined concrete cylinders using linear genetic programming, Materials and Structures 43(7): 963-983. http://dx.doi.org/10.1617/s11527-009-9559-y

Gandomi, A. H.; Alavi, A. H.; Mirzahosseini, M. R.; Moghdas Nejad, F. 2011a. Nonlinear genetic-based models for prediction of flow number of asphalt mixtures, Journal of Materials in Civil Engineering ASCE 23(3): 1-18. http://dx.doi.org/10.1061/(ASCE)MT.1943-5533.0000154

Gandomi, A. H.; Alavi, A. H.; Yun, G. J. 2011b. Nonlinear modeling of shear strength of SFRCB beams using linear genetic programming, Structural Engineering and Mechanics 38(1): 1-25. http://dx.doi.org/10.12989/sem.2011.38.1.001

Gandomi, A. H.; Alavi, A. H. 2011. Multi-stage genetic programming: a new strategy to nonlinear system modeling, Information Sciences (in Press). http://dx.doi.org/10.1016/j.ins.2011.07.026

Golbraikh, A.; Tropsha, A. 2002. Beware of $\mathrm{q}^{2} !$, Journal of Molecular Graphics and Modelling 20(4): 269-276. http://dx.doi.org/10.1016/S1093-3263(01)00123-1

Hansen, J. B. 1968. A revised extended formula for bearing capacity, Danish Geotechnical Institute Bulletin 28.

Hoła, J.; Schabowicz, K. 2005. Application of artificial neural networks to determine concrete compressive strength based on non-destructive tests, Journal of Civil Engineering and Management 11(1): 23-32.

Javadi, A. A.; Rezania, M.; Mousavi Nezhad, M. 2006. Evaluation of liquefaction induced lateral displacements using genetic programming, Computers and Geotechnics 33(4-5): 222-233. http://dx.doi.org/10.1016/j.compgeo.2006.05.001

Kalinli, A.; Cemal Acar, M.; Gündüz, Z. 2011. New approaches to determine the ultimate bearing capacity of shallow foundations based on artificial neural networks and ant colony optimization, Engineering Geology 117: 29-38. http://dx.doi.org/10.1016/j.enggeo.2010.10.002

Kapliński, O.; Janusz, L. 2006. Three phases of multifactor modelling of construction processes, Journal of Civil Engineering and Management 12(2): 127-134.

Koza, J. 1992. Genetic programming, on the programming of computers by means of natural selection. Cambridge: MIT Press.

Kuo, Y. L.; Jaksa, M. B.; Lyamin, A. V.; Kaggwa, W. S. 2009. ANN-based model for predicting the bearing capacity of strip footing on multi-layered cohesive soil, Computers and Geotechnics 36: 503-516. http://dx.doi.org/10.1016/j.compgeo.2008.07.002

Malinowski, P.; Polarczyk, I.; Piotrowski, J. 2006. Neural model of residential building air infiltration process, Journal of Civil Engineering and Management 12(1): 83-88.

Meyerhof, G. G. 1963. Some recent research on the bearing capacity of foundations, Canadian Geotechnical Journal 1(1): 16-26. http://dx.doi.org/10.1139/t63-003

Meyerhof, G. G. 1950. The bearing capacity of sand: $\mathrm{PhD}$ thesis, University of London.
Milani, G.; Milani, F. 2008. Genetic algorithm for the optimization of rubber insulated high voltage power cables production lines, Computers and Chemical Engineering 32: $3198-3212$. http://dx.doi.org/10.1016/j.compchemeng.2008.05.010

Muhs, H.; Elmiger, R.; Weiß, K. 1969. Sohlreibung und Grenztragfähigkeit unter lotrecht und schräg belasteten Einzelfundamenten. Deutsche Forschungsgesellschaft fur Bodenmechanik (DEGEBO). Berlin. HEFT 62.

Muhs, H.; Weiß, K. 1971. Untersuchung von Grenztragfähigkeit und Setzungsverhalten flachgegründeter Einzelfundamente im ungleichförmigennichtbindigen Boden, Deutsche Forschungsgesellschaft fur Bodenmechanik (DEGEBO) 69. Berlin.

Muhs, H.; Weiß, K. 1973. Inclined load tests on shallow strip footings, in Proceedings of the $8^{\text {th }}$ International Conference on Soil Mechanism and Foundation Engineering 2: 173-179.

Narendra, B. S.; Sivapullaiah, P. V.; Suresh, S.; Omkar, S. N. 2006. Prediction of unconfined compressive strength of soft grounds using computational intelligence techniques: a comparative study, Computers and Geotechnics 33(3): 196-208. http://dx.doi.org/10.1016/j.compgeo.2006.03.006

Oltean, M.; Grosan, C. 2003. A comparison of several linear genetic programming techniques, Complex Systems 14(4): $1-29$.

Ozkaya, B.; Demir, A.; Bilgili, M. S. 2007. Neural network prediction model for the methane fraction in biogas from field-scale landfill bioreactors, Environmental Modelling \& Software 22: 815-822. http://dx.doi.org/10.1016/j.envsoft.2006.03.004

Padmini, D.; Ilamparuthi, K.; Sudheer, K. P. 2008. Ultimate bearing capacity prediction of shallow foundations on cohesionless soils using neurofuzzy models, Computers and Geotechnics 35: 33-46. http://dx.doi.org/10.1016/j.compgeo.2007.03.001

Poli, R.; Langdon, W. B.; McPhee, N. F.; Koza, J. R. 2007. Genetic programming: an introductory tutorial and a survey of techniques and applications, Technical report [CES475]. University of Essex.

Prandtl, L. 1921. Über die Eindringungsfestigkeit (Härte) plastischer Baustoffe und die Festigkeit von Schneiden (On the penetrating strengths (hardness) of plastic construction materials and the strength of cutting edges), Zeitschrift für Angewandte Mathematik und Mechanik 1(1): 15-20. http://dx.doi.org/10.1002/zamm.19210010102

Reissner, H. 1924. Zum Erddruckproblem (Concerning the earth-pressure problem), in Proceedings $1^{\text {st }}$ International Congress of Applied Mechanics, Delft: 295-311.

Roy, P. P.; Roy, K. 2008. On some aspects of variable selection for partial least squares regression models, QSAR \& Combinatorial Science 27(3): 302-313. http://dx.doi.org/10.1002/qsar.200710043

Schabowicz, K.; Hola, B. 2007. Mathematical-neural model for assessing productivity of earthmoving machinery, Journal of Civil Engineering and Management 13(1): 47-54

Šešok, D.; Belevicius, R. 2008. Global optimization of trusses with a modified genetic algorithm, Journal of Civil Engineering and Management 14(3): 147-154. http://dx.doi.org/10.3846/1392-3730.2008.14.10

Šešok, D.; Mockus, J.; Belevicius, R.; Kačeniauskas, A. 2010. Global optimization of grillages using simulated annealing and high performance computing, Journal of Civil Engineering and Management 16(1): 95-101. http://dx.doi.org/10.3846/jcem.2010.09

Smith, G. N. 1986. Probability and statistics in civil engineering. London: Collins. 
Sonmez, R.; Ontepeli, B. 2009. Predesign cost estimation of urban railway projects with parametric modeling, Journal of Civil Engineering and Management 15(4): 405-409. http://dx.doi.org/10.3846/1392-3730.2009.15.405-409

Taylor, D. W. 1948. Fundamentals of soil mechanics. New York: John Wiley and Sons.

Terzaghi, K. 1943. Theoretical soil mechanics. New York: John Wiley and Sons. http://dx.doi.org/10.1002/9780470172766

Vesic, A. S. 1973. Analysis of ultimate loads of shallow foundations, Journal of the Soil Mechanics and Foundations Division 99(1): 45-73.
Vesic, A. S. 1975. Bearing capacity of shallow foundations, Chap. 3, in Foundation Engineering Handbook, Winterkorn, H.F. and Fang, H. Y. (Ed.). New York: Van Nostrand Reinhold.

Weise, T. 2009. Global optimization algorithms - theory and application [online]. Germany. Available from Inernet: http://www.it-weise.de

Weiß, K. 1970. Der Einfluß der Fundamentform auf die Grenztragfa"higkeit flachgegru"ndeter Fundamente. Deutsche Forschungsgesellschaft fur Bodenmechanik (DEGEBO) 65. Berlin.

\section{Appendix A}

\section{The optimum LGP program for the prediction of $q_{u l t}$}

The following LGP program can be run in the Discipulus interactive evaluator mode or can be compiled in $\mathrm{C}++$ environment. (Note: $\mathrm{v}[0], \ldots, \mathrm{v}[4]$ respectively represent $B, D, L / B, \gamma$, and $\phi . \mathrm{f}[0]$ holds the output.)

float DiscipulusCFunction(float $\mathrm{v}[]$ )

\{long double f[8];

long double tmp $=0$;

int cflag $=0$;

$\mathrm{f}[0]=\mathrm{f}[1]=\mathrm{f}[2]=\mathrm{f}[3]=\mathrm{f}[4]=\mathrm{f}[5]=\mathrm{f}[6]=\mathrm{f}[7]=0$;

L0: $\quad \mathrm{f}[0]+=\mathrm{v}[0]$;

L1: $\quad \mathrm{f}[0]+=\mathrm{f}[0]$;

L2: $\quad \mathrm{f}[1]+=\mathrm{f}[0]$;

L3: $\quad \mathrm{f}[0] /=\mathrm{v}[0]$;

L4: $\quad \mathrm{f}[0]+=5 \mathrm{f}$;

L5: $\quad \mathrm{f}[0]^{*}=-5 \mathrm{f}$;

L6: $\quad \mathrm{f}[0]+=\mathrm{v}[4]$;

L7: $\quad \mathrm{f}[1]^{*}=\mathrm{f}[0]$;

L8: $\quad \mathrm{f}[0] /=\mathrm{v}[2]$;

L9: $\quad \mathrm{f}[0]^{*}=\mathrm{f}[0]$;

L10: $\quad \mathrm{f}[0]^{*}=\mathrm{v}[2]$;

L11: $\quad \mathrm{f}[0] /=0.25 \mathrm{f}$;

L12: $\quad \mathrm{f}[0] /=0.449999988079071 \mathrm{f}$;

L13: $\quad \mathrm{f}[0]+=\mathrm{v}[4]$;

L17: $\quad \mathrm{f}[0]+=\mathrm{v}[3]$;

L18: $\mathrm{f}[0]^{*}=\mathrm{v}[1]$;

L19: $\quad \mathrm{f}[0]^{*}=\mathrm{v}[1]$;

L20: $\quad \mathrm{f}[0]+=5 f$;

L21: $\quad \mathrm{f}[0]+=\mathrm{f}[1]$;

L22: $\quad \mathrm{f}[0] /=1.5 \mathrm{f}$;

L23: $\quad \mathrm{f}[0]+=\mathrm{f}[1]$;

L24: $\quad \mathrm{f}[0] /=1.5 \mathrm{f}$;

L25: $\quad \mathrm{f}[0]^{*}=\mathrm{v}[4]$;

L26:

if (!_finite(f[0])) f[0] $=0$; return $\mathrm{f}[0]$; $\}$ 
Ehsan SADROSSADAT. Received his BSc degree in Civil Engineering from Islamic Azad University of Mashhad (IAUM) in 2008, Mashhad, Iran. He is now an MSc student of Geotechnical Engineering in Kerman Graduate University of Technology, Kerman, Iran. He has published about 15 scientific papers in international journals, national conferences. His research interest include applications of artificial intelligence techniques to civil engineering problems, reliability-based design (RBD) in geotechnical engineering, shallow foundations, piles and micro piles, soil improvement (lime and cement), pavement and composite materials.

Fazlollah SOLTANI. Received his BSc degree in Civil Engineering from Sistan and Baloochestan University (Iran) in 1989. In 1994, he received his MSc degree from the Insa de Lyon (France). In 1997, he received his PhD degree from the same university in Geotechnical Engineering. He is a member of teaching faculty in the Civil Engineering Department at Kerman graduate University of Technology (Iran). He has published one book and more than 40 scientific papers in international journals, national and international conferences. His research interest include unsaturated soil permeability, application of geosynthetics in civil engineering, slope stability analysis, liquefaction phenomena, shallow foundation, piles and micro piles.

Seyyed Mohammad MOUSAVI. Received his BSc in Civil Engineering form Sharif University of Technology and MSc degree in Structural Engineering from Taribat Modarres University, Tehran, Iran. He is currently a PhD student of Geography and Urban Planning at Science and Research branch of Islamic Azad University, Tehran, Iran. He has published over 10 papers in international journals, national conferences.His research interests include computer-aided modeling of civil engineering problems, earthquake engineering, and composite materials.

Seyed Morteza MARANDI. Received his BSc degree in Civil Engineering from Texas University in 1978. In 1980, he received his MSc degree from the same University. Immediately after graduating, he returned back home and was employed as a member of teaching faculty at the Civil Engineering Department at Shahid Bahonar University, Kerman, Iran. He received his PhD Degree from University of Leeds in Geotechnical Engineering in 1996. He has published two books and more than 130 scientific papers in international journals, national and international conferences. His research interest include seepage analysis in earth and earth-rock dams, slope stability analysis, liquefaction phenomena, piles and micro piles, application of geo-synthetics in civil engineering, and soil improvement.

Amir H. ALAVI. Graduated in Civil and Geotechnical Engineering from Iran University of Science \& Technology (IUST), Tehran, Iran. He used to be a lecturer in Eqbal Lahoori Institute of Higher Education and serve as a researcher in School of Civil Engineering at IUST. He is currently a researcher at the Department of Civil \& Environmental Engineering at Michigan State University (MSU), MI, USA. He has over 90 publications in book chapters, indexed journals, and conference proceedings. He has registered two patents and published two books in Elsevier. He is on the editorial board of two journals and serves as a regular reviewer for several indexed journals (Elsevier, Springer, Wiley, Taylor \& Francis, etc.). As of October 2013, he has been selected among the Scholar Google 200 Most Cited Authors in Civil Engineering. His current research at MSU is focused on Structural Health Monitoring of Pavement Systems Using Self-Powered Strain Sensors. His research interests include analysis and design using metaheuristic, statistical and probabilistic methods, pavement materials and pavement design, geotechnical engineering, and composite materials. 